\title{
Geomechanical Influences in Water Injection Projects: An Overview
}

\author{
K. Heffer ${ }^{1}$ \\ 1 Industrial Fellow, Heriot-Watt University - United Kingdom \\ e-mail: kes.heffer@pet.hw.ac.uk
}

Résumé - Présentation générale des effets géomécaniques induits par l'injection d'eau dans les réservoirs - Au cours de l'injection d'eau, l'augmentation des pressions interstitielles et la diminution de température entraînent une diminution des contraintes effectives horizontales, notamment à proximité des puits d'injection. Ce déchargement mécanique peut activer des failles et des fractures naturelles au sein du réservoir, du recouvrement, des couches inférieures ou des fractures hydrauliques à proximité des puits d'injection. Ces effets géomécaniques induisent des modifications anisotropes de la perméabilité, généralement en augmentation, qui devraient être intégrées dans la simulation du réservoir, particulièrement du point de vue de la configuration des puits, afin d'en obtenir les meilleurs avantages commerciaux.

\begin{abstract}
Geomechanical Influences in Water Injection Projects: An Overview - During water injection, increasing pore pressures and decreasing temperatures imply reductions in effective horizontal stresses, particularly in proximity to injection wells. This unloading can lead to activation of the natural faults and fractures by brittle failure in the body of the reservoir, over- or under-burden, or to the creation of hydraulic fractures in the vicinity of injection wells. These geomechanical changes will be associated with anisotropic permeability changes, usually increases, that should be incorporated into reservoir simulation, particularly with the objective of configuring the original, or infill, well pattern to the best commercial advantage.
\end{abstract}




\section{STRESS STATE CRITICALITY}

Strongly controlling these effects is the in situ stress state. The evidences of earthquake statistics, earthquakes triggered by other earthquakes, fault and fracture statistics, intepretations of full in situ stress tensors from image logs, and occurrences of microseismicity during perturbation, all point to stress states in the lithosphere being naturally in a self-organized critical state (e.g. Bak, 1997; Grasso and Sornette, 1998; Sanderson and Zhang, 1999; Townend and Zoback, 2000). Data from seismicity studies indicate that small stress changes $(\sim 1$ bar $[0,1 \mathrm{MPa}])$ are often sufficient to induce further seismicity (e.g. Stein, 1999). Therefore it is likely that the comparatively large stress changes induced by the field development will perturb this generally metastable state.

\section{STRESS-DEPENDENT PERMEABILITY}

As waterflooding moves the stress state in the formation towards brittle failure, the permeability is likely to increase. This is certainly true for hard rock formations. Laboratory experiments have indicated that permeability of high porosity, weaker, sands tends to decrease despite dilatancy on brittle failure (e.g. Zhu and Wong, 1997). However, those experiments have all been run with increasing average stresses; it is arguably more probable that decreasing stress states will also cause conductive fractures as they fail in brittle shear. The map of Figure 1 generalises the stress dependence of permeability. The stress perturbations will be most intense close to injector wells, and hence the phenomenon of "thermal fracturing". Pressure fall-off and hydraulic impedance tests generally indicate that a typical distance for propagation of continuous hydraulic fractures from injectors is of order $100 \mathrm{~m}$. However the stress perturbations can still be sufficient for shear failure across large parts of a critically stressed reservoir, and widespread anisotropic changes to the effective permeability can be induced by the waterflooding.

\section{FLOOD DIRECTIONALITY - AGGREGATED FIELD DATA STATISTICS}

Aggregations of data from many field cases of secondary and tertiary floods support the above statements. Heffer and Lean (1993) examined the flood breakthrough characteristics (Fig. 2a) of over 80 fields and determined that the anisotropy of breakthrough was strongly correlated with the local azimuth of maximum principal horizontal stress axis (Fig. $2 b$ and Fig. 3). The data was also consistent with the activation, particularly in shear, of natural fractures by the flooding as an explanation for this correlation, even though the natural fractures do not provide an obvious contribution to the initial permeability in the reservoir (i.e. the field may not be "naturally fractured" with its conventional meaning). Numerical geomechanical modeling of the areal influence of cooling, coupled with fluid flow gave rise to an areal pattern of shear zones (relative to $S_{h \max }$ ) that closely resembles the peaks in the frequencies of the field breakthrough orientations for "unfractured" reservoirs (Fig. 2c; Heffer and Koutsabeloulis, 1993).

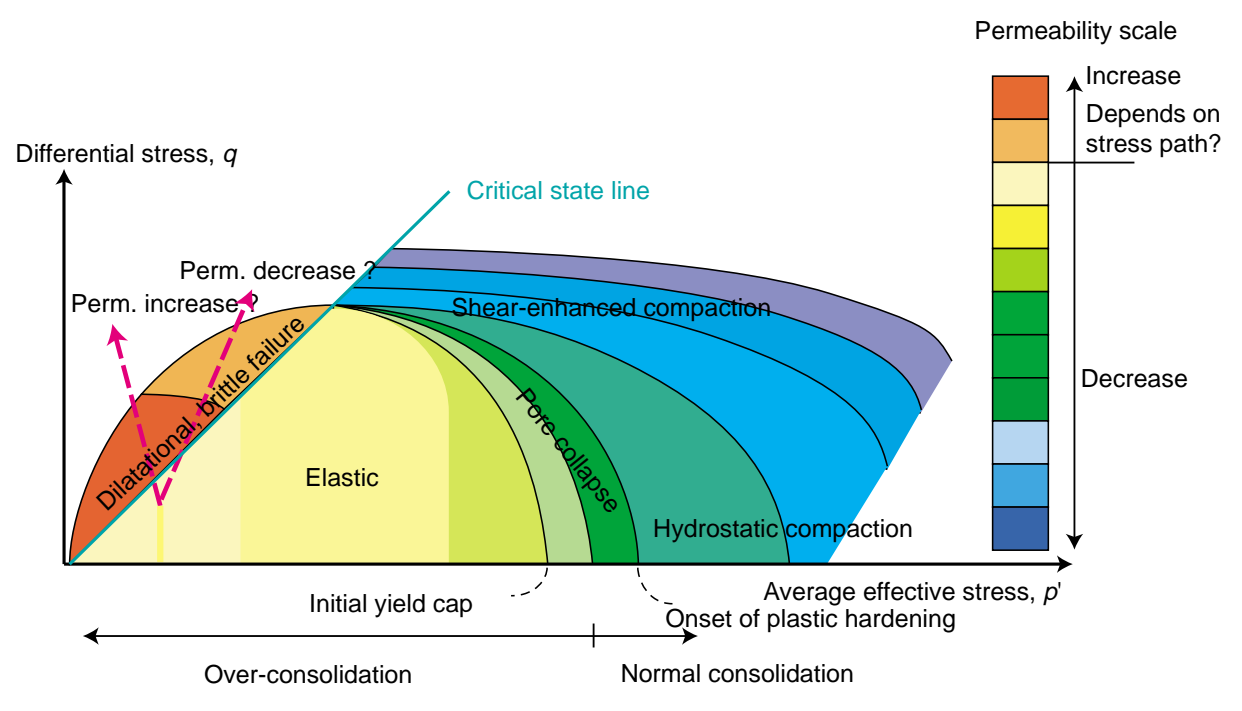

Conceptual after Zhu and Wong (1997) and Crawford et al. (1999)

Figure 1

Generalised permeability-stress map. 


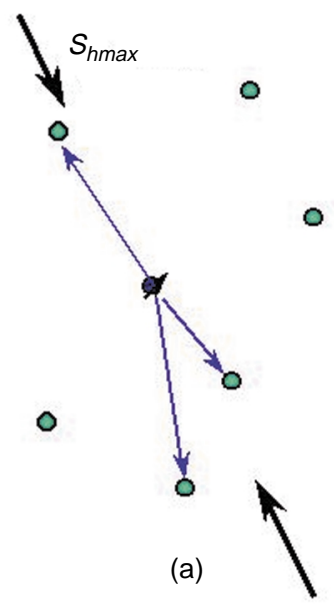

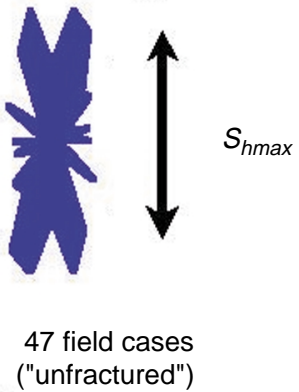

(b)

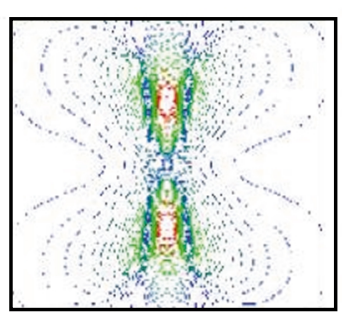

Numerical modeling

(c)

Figure 2

Stress and flood directionality.

a): example of breakthrough paths from an injector; b): orientational frequency of major axes of breakthrough in 47 "unfractured" fields shows peaks at small angles either side of $S_{\text {hmax }}$, as reproduced in numerical modeling (c).

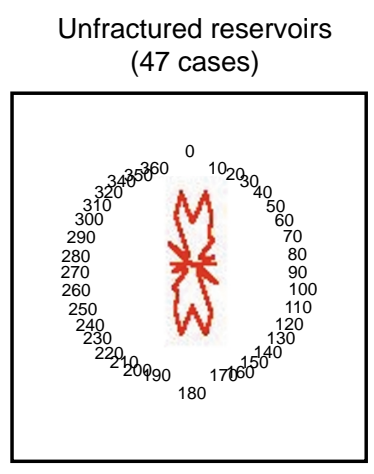

(a)

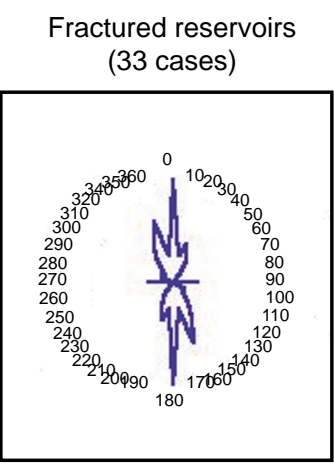

(b)

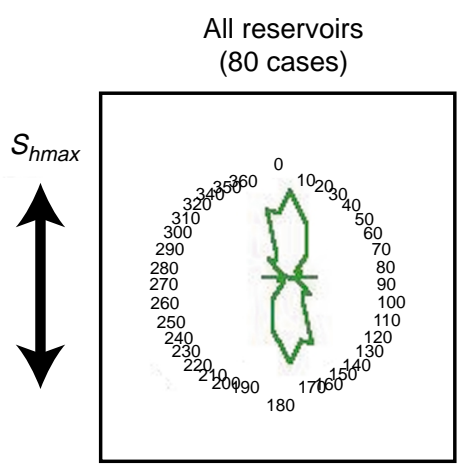

(c)

Figure 3

Flood directionality and "fractures". The bias in major azimuthal axes of breakthrough towards $S_{\text {hmax }}$ is irrespective of whether the reservoir is deemed "naturally fractured" or not.

\section{FLOOD DIRECTIONALITY - SPECIFIC FIELDS}

Field A. Extensive tracer studies in this large field under pattern waterflood were able to distinguish tracer breakthroughs along conductive faults. Prediction of heterogeneities in the modern-day stress distribution across the field was made with areal distinct element modeling, in which fault traces were allowed to slip according to a simple Mohr Coulomb's Law. With boundary tractions on the model chosen to match the average stress state orientation measured at a number of wells, an equilibrium distribution of stresses was obtained, which could be interrogated at all fault trace segments. It was found that the modeled axes of $S_{h \max }$ close by the conductive faults were all subparallel to the fault strike
(Fig. 4) implying that the minimum principal stress axis was acting suborthogonally to those faults, giving the best chance for dilatation and conductivity (Fig. 5).

Field B. A measure of areal anisotropy that was used in this field (which is also under a pattern waterflood) was obtained from the temporal correlations of fluctuations in production or injection rates at pairs of wells across the field (Fig. 6). If rates at a well pair fluctuated in phase together, a positive correlation coefficient was calculated; whilst negative correlation coefficients were obtained for anti-phase fluctuations. Strengths of the correlation coefficients were examined according to the orientations of the lines between injector-producer pairs relative to the local azimuth of $S_{h \max }$. It was found that the field could be split into roughly equal 


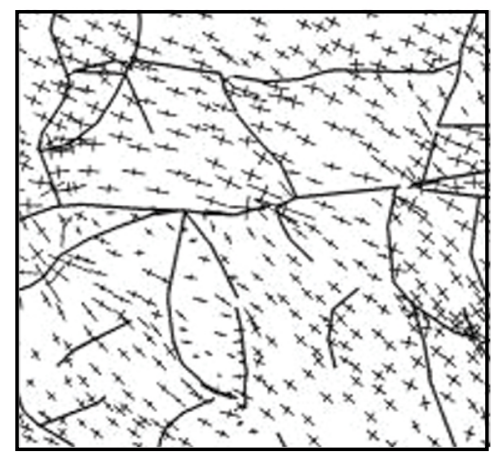

(a)

Stress vectors predicted by distinct element modeling

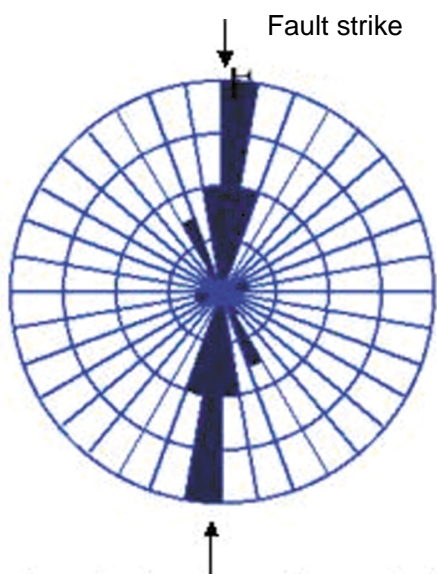

Orientation of modeled $S_{\text {hmax }}$ near conductive faults relative to strike of fault

Figure 4

Field A. a): modeled axes of principal horizontal stresses (maximum is longer); b): orientational distribution of conductive faults relative to local directionof $S_{\text {hmax }}$.

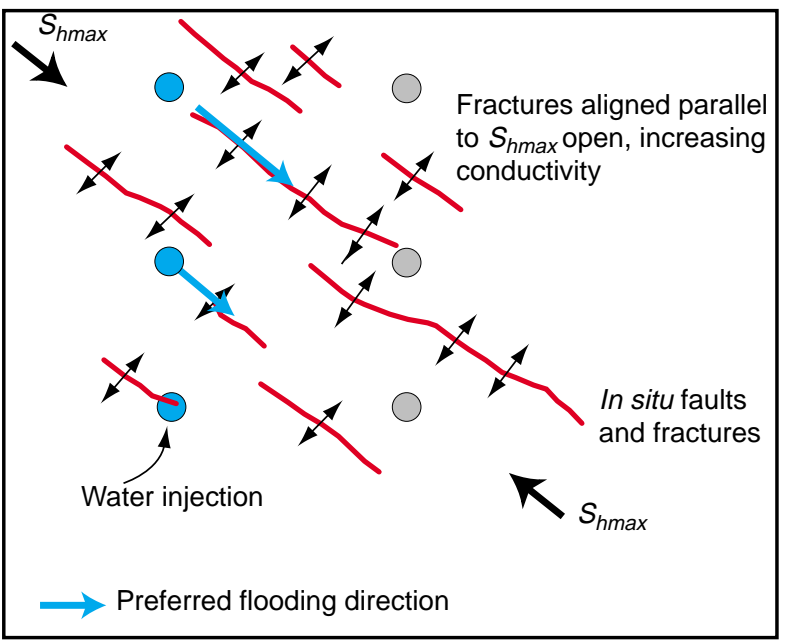

Figure 5

Fault strike and stress. Faults subparallel to $S_{h \max }$ are more easily dilated to become conductive to water.

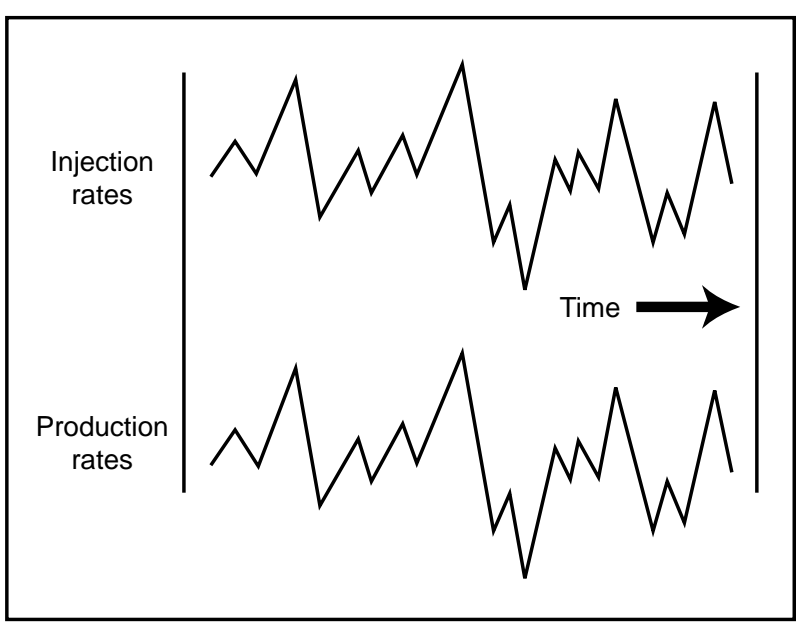

Figure 6

Idealised depiction of rate correlations. The (Spearman rank) correlation coefficients range from -1 for perfectly anticorrelated; to 0 for completely uncorrelated; to +1 for a perfectly correlated pair of sequences (as shown in this example). areas, between which the orientational distributions of measured $S_{h \max }$ were approximately orthogonal; the respective azimuthal distributions of the strengths of correlation coefficients in the 2 parts of the field also showed the same approximate 90 degree rotation (Fig. 7).

Furthermore, an areal interpolation of $S_{\text {hmax }}$ orientations allowed the watercut observations at wells to be plotted as a function of the local orientation of $S_{\text {hmax }}$ (Fig. 8): the peaks in watercut were observed to be very closely aligned with one or other of the fault trends across the field. The interpretation of this observation is that faults are conductive when striking subparallel to the local orientation of $S_{h m a x}$; in such situations the faults are more conductive and allow water to breakthrough to producers more readily. VISAGE ${ }^{\mathrm{TM}}$ (VIPS, 2001) finite element modelling allowed estimation of the magnitudes of the stresses that are consistent with the 


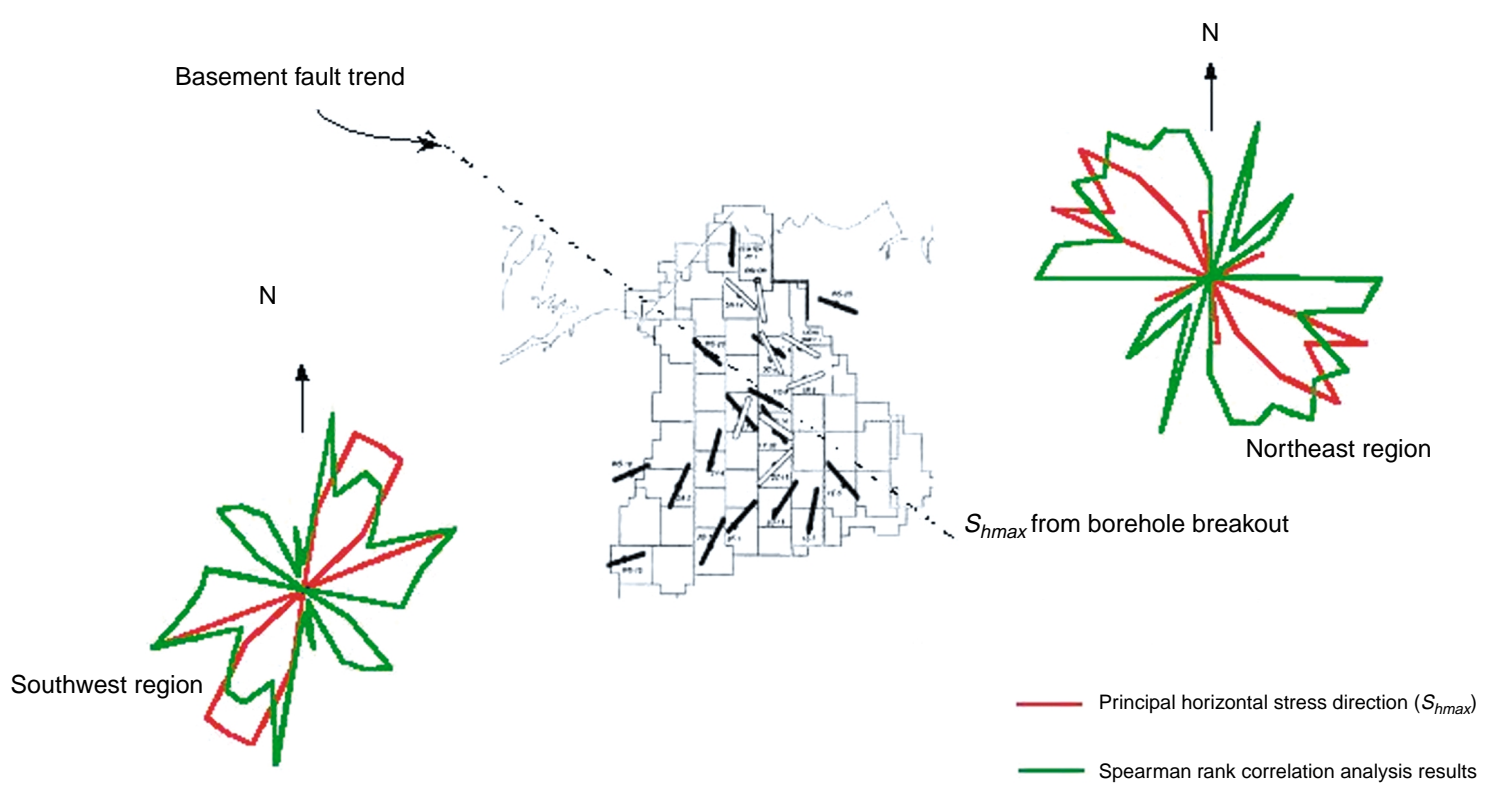

Figure 7

Results of rate correlation analysis for 2 parts of field B. The orientational distribution of strengths of correlation coefficient follow those of the maximum horizontal principal stresses. The line dividing the 2 parts of the field overlies a major basement fault.

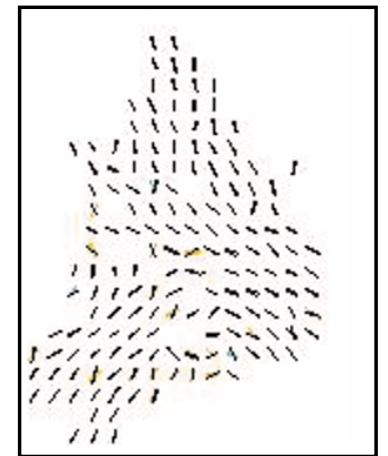

(a)

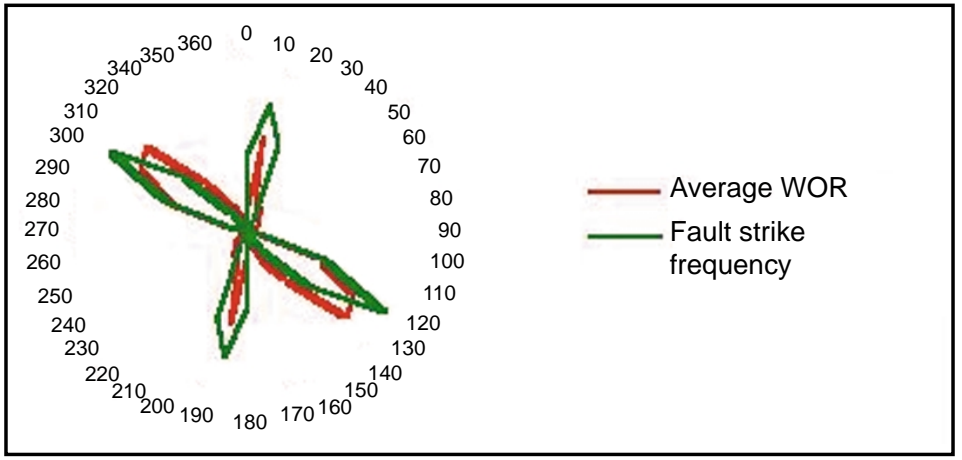

(b)

Figure 8

Field B. a): interpolated map of orientations of $S_{\text {hmax }}$ across field; b): (red) average produced water/oil ratio at producing wells as a function of the local orientation of $S_{h \max }$ compared with (green) the azimuthal distribution of fault strikes.

observed stress orientations and also with equilibrium on the faults in the field. It was found that the areas of low modeled magnitudes of minimum principal stress (where the rockfracture complex is loosely compressed) were collocated with areas of high watercuts in the field, again suggesting the involvement of conductive faults in water breakthrough (Fig. 9). This field data strongly supports the concept that the conductivity of faults is dependent upon both the orientation and the magnitudes of the local stress state (e.g. Townend and Zoback, 2000). Further details of these and other field studies are given in Heffer et al. (1995).

\section{RATE CORRELATIONS AS STRAIN INDICATORS}

Similar exercises in 6 other fields gave an aggregated orientational distribution of strengths of rate correlations that was markedly biased towards $S_{\text {hmax }}$ (Fig. 10a). In fact, on average, the correlation coefficient for well pairs aligned along the local direction of $S_{h \text { min }}$ was found to be negative. This implies, for example, that an increase in rate at an injector is associated with a decrease at a producer offset aligned along Shmin; ostensibly a contradiction of Darcy's Law! However, the orientational variations make good sense 
(a)

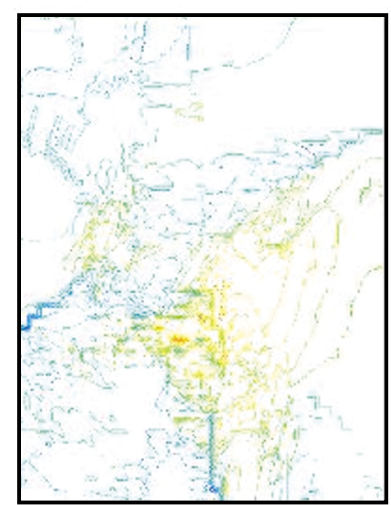

On $54 \times 66$ grid

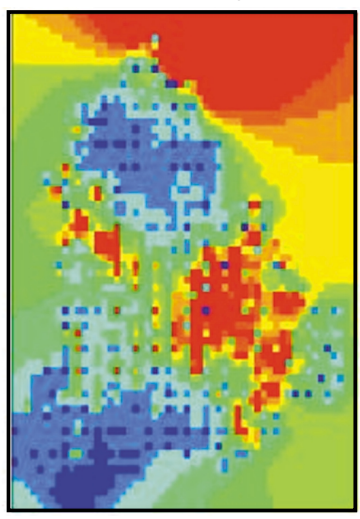

1.100

990

880

770

660

550

440

330

220

110

Figure 9

Field B. a): map of magnitudes of maximum principal horizontal stress modelled with VISAGE geomechanical simulator (stresses are more compressional in the sequence orange-yellow-green-turquoise-blue). b): map of cumulative water/oil ratios at producing wells across field (ignore artefacts of interpolation routine outside field area). There is a good spatial correlation between the areas of low stress magnitude (orange-yellow) and high water/oil ratio (red).

(a)

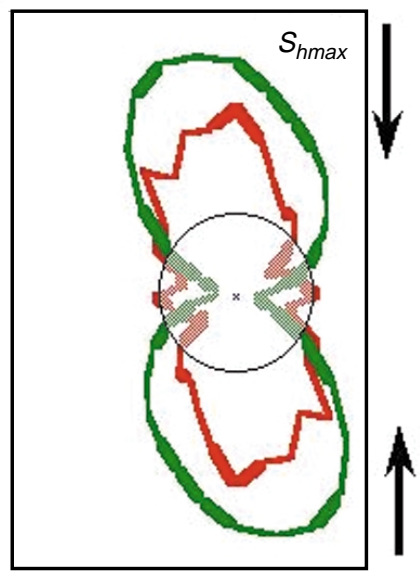

(b)

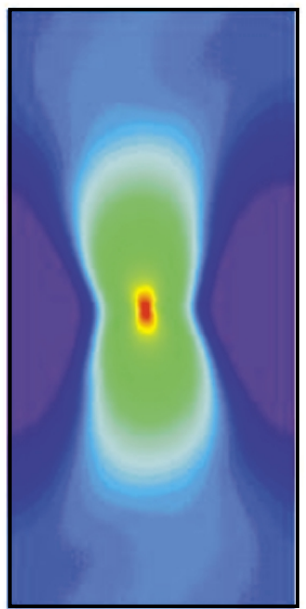

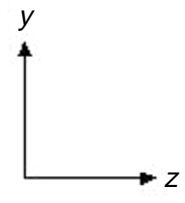

Figure 10

a): aggregated orientational distribution of rate correlation coefficients relative to direction of local $S_{h \max }$. The data was taken from 8 field areas and summarises the rate correlation coefficients of over half a million well pairs (green = raw data used; red = hi-pass filter applied to data before correlations; black circle $=$ zero correlation line).

b): theoretical areal distribution of correlaton in $x x$-strain at critical point (fall-offwith lag distance $\sim 1 / r$ ).

in terms of strain correlations: changes in strain in the vicinity of one well, which will be manifest as fracture/fault conductivity changes, are associated with particular orientational patterns of strain changes at offset locations. Figure $10 \mathrm{~b}$ shows the theoretical spatial autocorrelation of $x x$-strains, which would be pertinent to $S_{h \max }$ directed along the $y$-axis.

A further feature of the field data that is even more at odds with conventional hydrology is that some of the most significant correlations are large-range; indeed between well pairs at opposite ends of the field. The latter finding is exemplified in the data from field B, which is shown as stacked correlation coefficients in Figure 11 (consider this diagram as having all injectors stacked at the central point, and the colours as indicating the average strength of rate correlation coefficients at offset points around the injectors). The high values of correlation at points near the edges of the spatial lags can be seen in the figure. Although the longrange nature of the correlations is not yet fully understood, a clue exists in yet another feature of the data: there is a strong hint of the fault trends in the field in the autocorrelation 


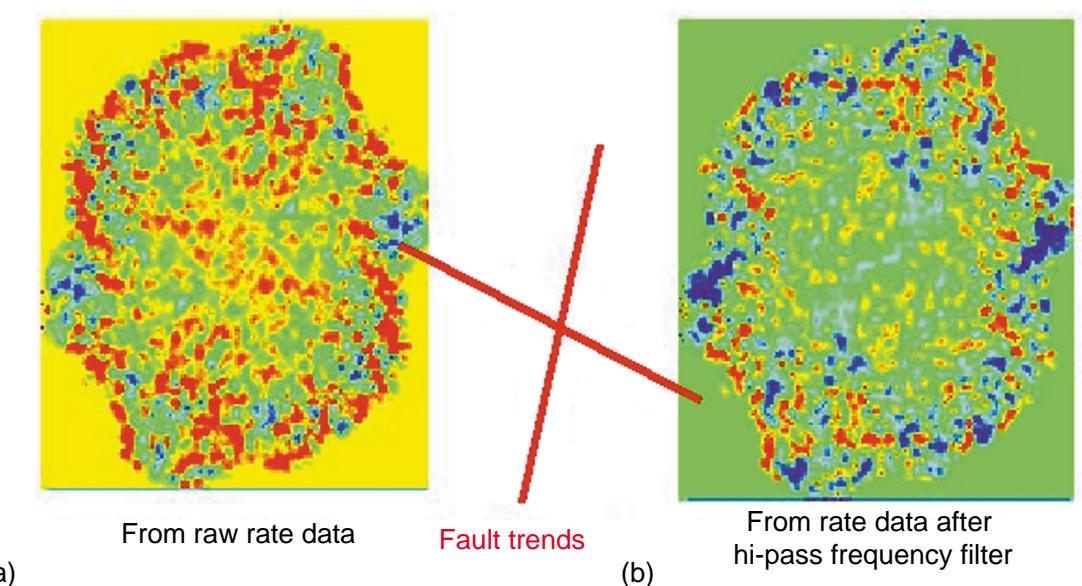

Figure 11

Field B. Stacked rate correlations. Colours depict the average strength of rate correlation coefficient for spatial lags relative to the central point. Red indicates highly positive. Dark blue indicates highly negative. Note the boundary highs and the trends parallel to faulting trends in the field.

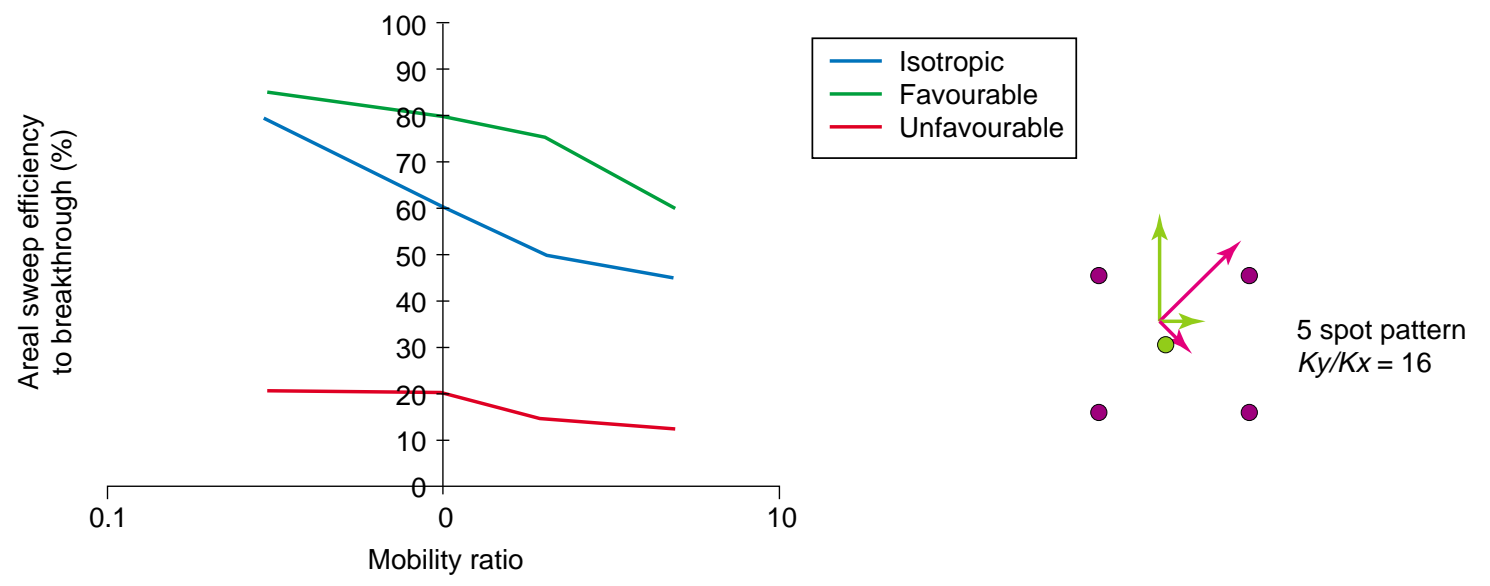

Figure 12

The prize - theory. Classical calculations of the sensitivity of areal sweep efficiency of a flood to the alignment of the five-spot well pattern in a reservoir of anisotropic permeability. The sweep efficiency is quoted for the time of water breakthrough. The efficiency is highly dependent upon whether the well pattern is aligned favourably (green) or unfavourably (red). Compared with curve for an isotropic reservoir (blue). All plotted against the mobility ratio of the injected/swept fluids (after Caudle and Loneric, 1960).

(Fig. 11). General deformation occurring during field development involves movement on the pre-existing faults and fractures under the influence of the in situ stress state and induced stress changes, and is thus strongly coupled with permeability changes and the fluid flow in the reservoir. The coupled system is at or near a critical point which is characterised by long-range correlations. It is surmised that the boundary to the field focuses correlated strain changes.

\section{PRACTICALITIES/CONCLUSIONS}

The above field data and theoretical considerations imply that stress state characterization should be a prime component of most, if not all, reservoir description and simulation exercises for waterflood and IOR projects. Current industry practice generally ignores this parameter for reservoir engineering, despite having realized for many decades the strong 
sensitivity of sweep efficiency to any anisotropy in the reservoir permeability (e.g. Fig. 12, after Caudle and Lonaric, 1960). Classical calculations of such sensitivity have assumed static permeabilities; it is quite possible that a coupled system at a critical point is even more sensitive to anisotropy. The production data available from field B supports the validity of such sensitivities (Fig. 13). Coupled geomechanical and fluid flow simulation has now been commercially available for several years to examine these issues, but to the operational reservoir engineer the additional overhead of geomechanics is just an extra headache on top of those prevalent in conventional reservoir engineering. The lack of adequate data, expertise and quick tools usually means that the issues are ignored: it is often possible to explain isolated field data in terms of conventional uncertainties. This situation will only be improved by more awareness and education in the topic of geomechanics, further field cases, and by the availability of more rapid tools to complement benchmark runs of a coupled geomechanicsflow simulator. The potential prize is very significant!

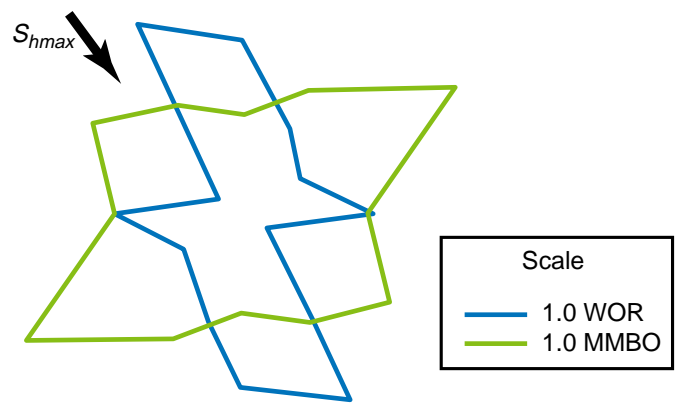

Figure 13

The prize - data from field B. Azimuthal plots of cumulative oil production (green); and cumulative water/oil ratio (blue) at producing wells as a function of the relative alignment of the nearest injector well. Note that the oil production is greatest whilst the water oil ratios are lowest for producers aligned along the minimum horizontal principal stress axis from the nearest injector. The bars indicate the scale of production parameters.

\section{REFERENCES}

Bak, P. (1997) How Nature Works - The Science of Self-Organized Criticality, Oxford University Press, ISBN 0198513933.

Crawford, B.R., Hutcheon, R., Smart, B.G.D. and Yale, D.P. (1999) Coupled Mechanical Deformation and Fluid Flow in Experimentally Yielded Granular Reservoir Materials. $9^{\text {th }}$ ISRM Congress, Paris.

Caudle, B.H. and Lonaric, I.G. (1960) Oil Recovery in Five-Spot Pilot Floods, Trans AIME, 219, 132-136.

Grasso, J.R. and Sornette, D. (1998) Testing Self-Organized Criticality by Induced Seismicity, J Geophys Res, 103, No B12, 29, 965-29, 987.

Heffer, K.J., Fox, R.J., McGill, C.A. and Koutsabeloulis, N.C. (1995) Novel Techniques Show Links between Reservoir Flow Directionality, Earth Stress, Fault Structure and Geomechanical Changes in Mature Waterfloods. SPE 30711 Presented at the SPE Annual Technical Conference and Exhibition, Dallas, 22-25 October, 1995 (republished in SPE Journal, 2, 2, 91-98, June 1997).

Heffer, K.J. and Koutsabeloulis, N.C. (1993) Stress Effects on Reservoir Flow - Numerical Modelling Used to Reproduce Field Data, Proceedings of the Seventh European Symposium on Improved Oil Recovery, October 27-29, 1993. In New Developments in Improved Oil Recovery, Geological Society Special Publication, 84, ISBN 1-897799-22-5.

Heffer, K.J. and Lean, J.C. (1993) Earth Stress Orientation - A Control on, and Guide to, Flooding Directionality in a Majority of Reservoirs. Reservoir Characterization III, edited by Bill Linville, PennWell Books, Tulsa.

Sanderson, D.J. and Zhang, X. (1999) Critical Stress Localisation of Flow Associated with Deformation of Well-Fracture Rock Masses, with Implications for Mineral Deposits. In Fractures, Fluid Flow and Mineralization, McKaffery, K.J.W., Lonergan, L. and Wilkinson J.J. (eds) Geological Society, London, Special Publications, 155, 69-81.

Stein, R.S. (1999) The Role of Stress Transfer in Earthquake Occurrence. Nature, 402, 605-609.

Townend, J. and Zoback, M.D. (2000) How Faulting Keeps the Crust Strong. Geology, 28, 5, 399-402.

VIPS Limited (2001) VISAGE User's Guide, Version 7.6. VIPS (Vector International Processing Systems) Limited, Elm Lodge, North Street, Winkfield, Windsor, Berkshire SL4 4TE, UK.

Zhu, W. and Wong, T.F. (1997) The Transition from Brittle Faulting to Cataclastic Flow: Permeability Evolution. J Geophys Res., 102, B2, 3027-3041.

Final manuscript received in June 2002 